\title{
Efeito de fertilizante foliar sobre isolados de Sclerotinia sclerotiorum
}

\author{
Thayla Christiane Putrick ${ }^{1}$, Maria Luiza Nunes Costa $^{1}$, Gustavo de Faria Theodoro ${ }^{2}$ \\ ${ }^{1}$ Universidade Federal de Mato Grosso do Sul, Campus de Chapadão do Sul, Chapadão do Sul, Brasil. E-mail: \\ putrickthayla@yahoo.com.br, luiza.costa@ufms.br \\ ${ }^{2}$ Universidade Federal de Mato Grosso do Sul, Câmpus de Campo Grande, Campo Grande, Mato Grosso do Sul, Brasil. E-mail: \\ gustavo.theodoro@ufms.br
}

Recebido: 04/02/2017; Aceito: 22/03/2018

\begin{abstract}
RESUMO
O mofo branco, causado por Sclerotinia sclerotiorum, é uma doença muito importante para muitas culturas agrícolas e seu controle tem sido realizado por meio da adoção de medidas de forma integrada. Foi avaliada a ação antifúngica de um fertilizante foliar preparado com óleo essencial de laranja (Orobor N1@: nitrogênio 1\%, boro $0,22 \%$ ) sobre o crescimento micelial e germinação carpogênica de S. sclerotiorum. Os experimentos foram conduzidos em delineamento inteiramente casualizados, em esquema fatorial, utilizando-se cinco isolados do patógeno e seis concentrações do fertilizante foliar. Na avaliação do crescimento micelial, discos de BDA (6 mm) com micélio fúngico, foram depositados em placas de Petri contendo a mistura de BDA com o produto nas concentrações de $0,50,100,150,200$ e $250 \mathrm{~mL}$ por $100 \mathrm{~L}$ de água. Mediram-se diariamente os dois diâmetros ortogonais da colônia, até que o tratamento testemunha colonizasse todo o meio de cultura. Na germinação carpogênica, depositaram-se 16 escleródios por caixas gerbox contendo solo umedecido a $62 \%$ da capacidade de campo. Em seguida, foram adicionadas as respectivas concentrações do produto, atingindo assim $100 \%$ da capacidade de campo do solo. O número de escleródios germinados, estipes e apotécios formados foi mensurado. Verificou-se interação significativa entre concentrações e isolados para as variáveis estudadas. O fertilizante foliar inibiu o crescimento micelial e reduziu a formação de escleródios. Não houve redução da germinação carpogênica, da produção de estipes e apotécios de S. sclerotiorum de modo geral.
\end{abstract}

Palavras-chave: mofo branco, Citrus sinensis, controle integrado

\section{Effect of foliar fertilizer on Sclerotinia sclerotiorum strains}

\begin{abstract}
White mold, caused by Sclerotinia sclerotiorum, it is an important disease in many agricultural crops and his control has been made through the adoption of integrated methods. The antifungal activity of a foliar fertilizer made of orange essential oil was evaluated (Orobor $\mathrm{N} 1{ }^{\circledR}: \mathrm{N} 1 \%, \mathrm{~B} 0,22 \%$ ) on the mycelial growth and carpogenic germination of Sclerotinia sclerotiorum. The experiments were conducted in completely randomized design, in factorial scheme, using five pathogen isolates and six concentrations of the foliar fertilizer. The measure of mycelial growth, PDA discs $(6 \mathrm{~mm})$ with fungal mycelium they were laid up in petri dishes containing PDA + mixing the product in this concentration $0,50,100,150,200$ and $250 \mathrm{~mL} 100 \mathrm{~L}^{-1}$ of water. They were measured daily two orthogonal diameters of the colony until the control treatment colonized the entire culture medium. In carpogenic germination, was deposited 16 sclerotia/gerbox boxes containing moistened soil to $62 \%$ of the field capacity (FC) then applied to the same product concentration, completing $100 \%$ of the FC. The evaluations were performed at 30, 45, 60 and 75 days, measure the number of germinated sclerotia, stipes and apothecia were formed. We founded interaction between concentrations and isolates for all variables. The foliar fertilizer inhibited the mycelial growth, reduced the formation of sclerotia and did not inhibited the carpogenic germination of S. sclerotiorum.
\end{abstract}

Key words: white mold, Citrus sinensis, integrated control. 
O Sclerotinia sclerotiorum, fungo cosmopolita de hábito necrotrófico, pode sobreviver no solo por meio de estruturas de resistência conhecidas como escleródios. Segundo Boland e Hall (1994) é patogênico a 78 famílias, 278 gêneros e 408 espécies de plantas, infectando espécies economicamente importantes como soja, feijão, algodão, tomate, ervilha, ervilhaca, alface, chicória, repolho, couve-flor, cenoura, entre outras (HOMECHIN, 1982).

Este fungo causa a doença conhecida como mofo branco, que possui sintomas variados dependendo do hospedeiro e sinais típicos como a formação de micélio cotonoso e presença de escleródios (CASSETARI NETO et al., 2010). Os escleródios são formados pela agregação de hifas de Sclerotinia sclerotiorum e contribuem com a sobrevivência do patógeno no solo, mesmo em condições adversas (AGRIOS, 2005). Caso haja a germinação carpogênica dos escleródios, ocorre a formação de apotécios que liberam ascósporos, responsáveis pela infecção da parte aérea das plantas (ABDULLAH et al., 2008). Se houver a germinação miceliogênica, as hifas formadas podem invadir os tecidos jovens das plantas próximo ao solo por meio da produção de ácido oxálico e causar sua morte (BOLTON et al., 2006).

A doença causada por Sclerotinia sclerotiorum ocasiona perdas elevadas de produtividade e seu controle pode ser mais eficaz por meio da integração de métodos convencionais e alternativos (SUMIDA et al., 2015). Há relatos do efeito de fertilizantes foliares na redução da severidade de doenças de plantas de etiologia variada, causada tanto pela indução de resistência quanto pela ação direta do produto sobre o patógeno (KATSURAYAMA; BONETI, 2002; NOJOSA et al., 2009). Wordell Filho e Stadnik (2006) constataram que ciprodinil, fosfito de potássio, fertilizante foliar (03-00-16), calda bordalesa e calda bordalesa combinado com fosfito de potássio reduziram significativamente a severidade da mancha acinzentada causada por Botrytis squamosa em cebola. Reuveni et al. (2009) constataram que a aplicação foliar de $\mathrm{KH}_{2} \mathrm{PO}_{4}$ a $1 \%(\mathrm{p} / \mathrm{v})$ induziu resistência sistêmica e local a Leveillula taurica em pimentão cultivado em condições de casa-de-vegetação. Trabalhando com tomateiros ao campo em condições controladas, Abbasi et al. (2002) verificaram que a aplicação foliar de fosfato de potássio semanalmente sobre Xanthomonas campestris pv. vesicatoria reduziu a severidade da doença. Paula Júnior et al. (2009) verificaram que a aplicação de cloreto de cálcio e de silicato de cálcio, apenas na floração ou neste momento e dez dias depois, reduziram a incidência e a severidade do mofo-branco do feijoeiro, sem efeito no rendimento da cultura em condições de campo. Existem relatos do efeito da aplicação foliar de fertilizantes silicatados no controle de doenças de plantas (BUCK et al., 2006; GUÉVEL et al., 2007), porém, o efeito de fertilizantes foliares sobre os patógenos precisa ser melhor compreendido.

O objetivo deste trabalho foi avaliar o crescimento micelial e a germinação carpogênica in vitro de escleródios de diferentes isolados de Sclerotinia sclerotiorum empregando-se diferentes concentrações de um fertilizante foliar com óleo essencial da casca de laranja.

Os experimentos foram conduzidos no Laboratório de Fitopatologia da Universidade Federal do Mato Grosso do Sul, Campus de Chapadão do Sul. Os isolados utilizados na condução deste experimento foram obtidos na forma de escleródios junto a instituições de pesquisa e em lavouras comerciais localizadas no município de Chapadão do Sul, MS.

A partir dos isolados recuperados, foram produzidos os escleródios, em condições laboratoriais, necessários para a condução do projeto. Para a produção dos novos escleródios, foi utilizado o substrato de feijão (100 g de grãos de feijão $+10 \mathrm{~mL}$ de água), adicionado em frascos erlenmeyer. Este substrato foi autoclavado por 20 minutos a $120{ }^{\circ} \mathrm{C}$ e, após o resfriamento, foram adicionados cinco discos de micélio do fungo, com sete dias de idade. Posteriormente, os frascos foram incubados em câmara climatizada a $25 \pm 2{ }^{\circ} \mathrm{C}$, na ausência de luz, por 30 dias, conforme metodologia modificada de Garcia et al. (2012a). Após este período, os escleródios formados foram retirados dos frascos e lavados em água corrente.

Nos ensaios descritos a seguir, foi utilizado o delineamento experimental inteiramente casualizado (DIC) em esquema fatorial, com seis concentrações do fertilizante foliar e cinco isolados de Sclerotinia sclerotiorum. $\mathrm{Na}$ avaliação do crescimento micelial foram utilizados quatro repetições. Para a avaliação da germinação carpogênica foi utilizado três repetições. Conforme análise de variância os dados quantitativos foram transformados em $\sqrt{ }(\mathrm{x}+1)$ e foram verificados ajustes dos dados à regressão linear; para os dados qualitativos foi utilizado o teste de Scott-Knott com nível de significância de $5 \%$.

Para avaliar o efeito do fertilizante foliar Orobor N1®, preparado com óleo essencial de laranja (concentração não informada pelo fabricante), nitrogênio $(1 \%)$ e boro $(0,22 \%)$, foram utilizadas as seguintes concentrações: $0,50,100,150,200$ e $250 \mathrm{~mL}$ do produto comercial por $100 \mathrm{~L}^{-1}$ de água, as quais foram misturadas ao meio BDA e em seguida vertidas em placas de Petri. Após, a solidificação de discos de 6 $\mathrm{mm}$ de diâmetro, contendo micélio do fungo com sete dias de idade, foram transferidos para o centro das placas. As placas foram incubadas em câmara climatizada a $22 \pm 2^{\circ} \mathrm{C}$, com fotoperíodo de 12 horas, de acordo com a metodologia de Garcia et al. (2012b). 
As avaliações foram realizadas diariamente, iniciadas 24 horas após a incubação e encerradas 96 horas após, quando todas as testemunhas dos isolados utilizados atingiram toda a superfície do meio, mensurando-se o diâmetro das colônias em dois eixos ortogonais, com auxilio de régua milimetrada. Após 14 dias da implantação do experimento foram contados os escleródios produzidos em cada placa/tratamento.

Para a determinação do índice de velocidade de crescimento micelial (IVCM) utilizou-se a fórmula descrita por Oliveira (1992) e a porcentagem de inibição do crescimento micelial (PICM) obtida por meio da fórmula de Abbott (1925):

$$
\operatorname{IVCM}=\Sigma \frac{(\mathrm{D}-\mathrm{Da})}{\mathrm{N}}
$$

Em que: IVCM= índice de velocidade de crescimento micelial; $\mathrm{D}=$ diâmetro médio atual da colônia, em cm; Da = diâmetro médio da colônia do dia anterior, em cm; N= número de dias após a incubação.

$$
\mathrm{PICM}=\frac{(\mathrm{DTT}-\mathrm{DT})}{\mathrm{DTT}} \times 100
$$

Em que: $\mathrm{PICM}=$ porcentagem de inibição do crescimento micelial, em $(\%)$; DTT $=$ diâmetro do tratamento da testemunha, em $\mathrm{cm}$; DT = diâmetro do tratamento, em cm.

$\mathrm{O}$ experimento foi conduzido empregando-se solo esterilizado em autoclave duas vezes por 1 hora a 120 ${ }^{\circ} \mathrm{C} / 1$ atm, com um intervalo de 24 horas. Os escleródios produzidos foram desinfestados de acordo com a metodologia descrita por Delgado et al. (2007), havendo a imersão dos mesmos, por 30 segundos, em solução de hipoclorito de sódio a $2 \%$, seguida de imersão, pelo mesmo tempo, em água destilada esterilizada, procedimento este repetido três vezes. Posteriormente, foram mantidos em câmara de fluxo de ar sobre papel filtro até secarem.

Para garantir ambiente adequado para produção de estipes e apotécios, sem interferência do excesso de umidade, foi utilizada a capacidade de campo (CC) para umedecer o solo, conforme metodologia descrita por Napoleão (2007), sendo necessária adaptação para inclusão do fertilizante. Após distribuição de $200 \mathrm{~g}$ de solo seco por caixa tipo gerbox foi adicionada água destilada esterilizada nas parcelas para elevar o solo inicialmente seco até a condição de $62 \%$ da C.C., reservando o restante $(38 \%)$ para inclusão do fertilizante foliar. O produto comercial, à base de óleo essencial de laranja (Orobor $\mathrm{N} 1{ }^{\circledR}$ ) foi empregado nas concentrações de $0,50,100,150,200$ e $250 \mathrm{~mL}$ por $100 \mathrm{~L}$ de água. Incubação realizada em câmara climatizada a $19 \pm 2{ }^{\circ} \mathrm{C}$, fotoperíodo de 12 horas e manutenção do solo a $100 \%$ da CC durante todo o experimento
Para avaliações foram contados os escleródios germinados, estipes e apotécios formados por caixa; a primeira avaliação realizada aos 30 dias após a implantação do experimento e as restantes, distanciadas em 15 dias, até completar 75 dias de incubação. Detectou-se interação significativa $(\mathrm{p} \leq 0,05)$ entre isolados e concentrações do fertilizante foliar sobre índice de velocidade de crescimento micelial (IVCM), porcentagem de inibição do crescimento micelial (PICM) e produção de escleródios dos isolados de Sclerotinia sclerotiorum, aos 14 dias da implantação do experimento (Tabelas 1). Os dados obtidos foram ajustados ao modelo linear para cada isolado utilizado (Figuras 1 a 6).

Para o IVCM, observou-se que a testemunha após 96 horas, colonizou toda a placa. Na análise da Figura 1 percebe-se tendência linear na redução do IVCM conforme o aumento da concentração do produto, observando-se índice de velocidade de crescimento micelial zero a partir das doses de $215,7 \mathrm{~mL}_{100 \mathrm{~L}^{-1}}$ (S1), 224,4 mL $100 \mathrm{~L}^{-1}$ (S2), 221,5 mL $100 \mathrm{~L}^{-1}$ (S3) e $228,8 \mathrm{~mL} 100 \mathrm{~L}^{-1}(\mathrm{~S} 4)$. As concentrações testadas reduziram o índice de crescimento micelial do patógeno sobre o meio de cultura BDA (Figura 2), com inibição

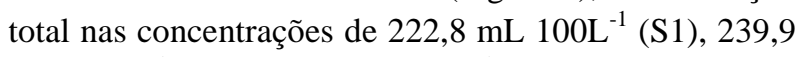

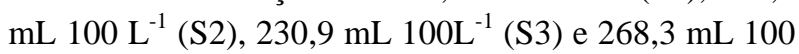
$\mathrm{L}^{-1}(\mathrm{~S} 4)$.

Tabela 1. Análise de variância do índice de velocidade do crescimento micelial, porcentagem de inibição do crescimento micelial e produção de escleródios dos isolados de Sclerotinia sclerotiorum, aos 14 dias da implantação do experimento em função das concentrações do produto comercial (Orobor $N 1^{\circledR}$ ).

\begin{tabular}{lcccc}
\hline FV $^{1}$ & G.L. $^{2}$ & IVCM $^{\mathbf{3}}$ & PICM $^{\mathbf{4}}$ & n $^{\mathbf{0}}$ Escleródios \\
\hline Isolado (I) & 4 & $1,23^{*}$ & $242,48^{*}$ & $46,82^{*}$ \\
Concentração (C) & 5 & $44,08^{*}$ & $26584,59^{*}$ & $1266,45^{*}$ \\
I x C & 20 & $0,37^{*}$ & $114,99^{*}$ & $32,09^{*}$ \\
\hline CV (\%) & & 25,09 & 5,68 & 33,22 \\
\hline
\end{tabular}

* Significativo a $5 \%$ de probabilidade; ${ }^{1} \mathrm{FV}$ : Fator de variação; ${ }^{2}$ G.L.: Grau de Liberdade; ${ }^{3}$ IVCM: índice de velocidade do crescimento micelial; ${ }^{4}$ PICM: porcentagem de inibição do crescimento micelial.

Tabela 2. Análise de variância da porcentagem de germinação carpogênica, número de estipes formados e número de apotécios formados, em função das concentrações do produto comercial (Orobor $\mathrm{N} 1{ }^{\circledR}$ ).

\begin{tabular}{lcccc}
\hline FV $^{\mathbf{1}}$ & G.L. $^{\mathbf{2}}$ & Germinação & $\mathbf{N E F}^{\mathbf{3}}$ & $\mathbf{N A F}^{\mathbf{4}}$ \\
\hline Isolado (I) & 4 & $49,11^{*}$ & $18,81^{*}$ & $21,19^{*}$ \\
Concentração (C) & 5 & $11,15^{*}$ & $18,81^{*}$ & $3,75^{*}$ \\
I x C & 20 & $13,58^{*}$ & $9,58^{*}$ & $7,05^{*}$ \\
\hline CV (\%) & - & 22,01 & 24,59 & 28,30
\end{tabular}

* Significativo a 5\% de probabilidade; ${ }^{1} \mathrm{FV}$ : Fator de variação; ${ }^{2} \mathrm{G} . \mathrm{L} .:$ Grau de Liberdade; ${ }^{3}$ NEF: número de estipes formados; ${ }^{4}$ NAF: número de apotécios formados. 

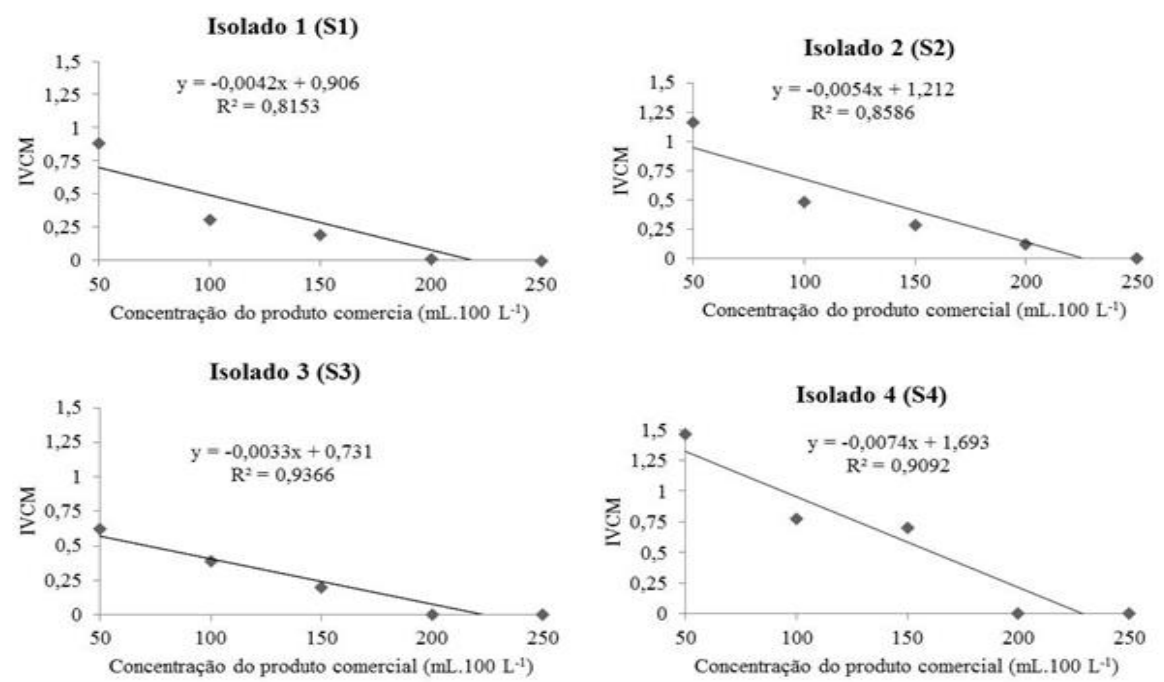

Figura 1. Índice de velocidade de crescimento micelial (IVCM) dos isolados de Sclerotinia sclerotiorum em relação às concentrações do fertilizante foliar $\left(\right.$ Orobor $N 1^{\circledR}$ ).
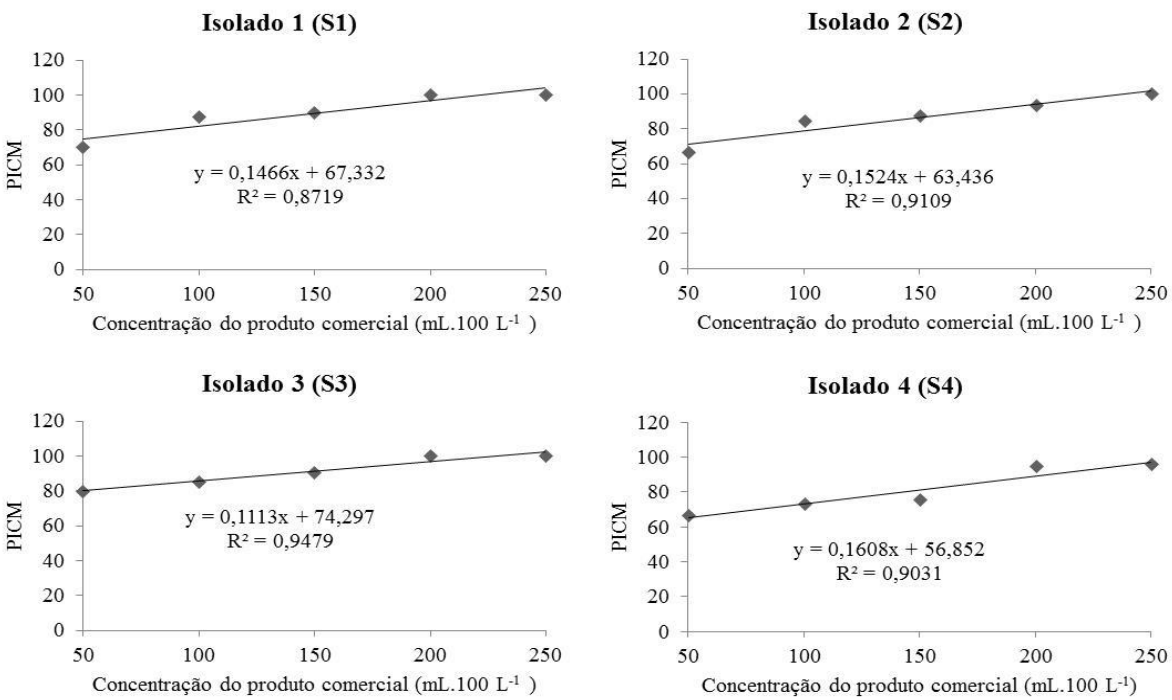

Figura 2. Porcentagem de inibição do crescimento micelial (PICM) dos isolados de Sclerotinia sclerotiorum em relação às concentrações do fertilizante foliar $\left(\right.$ Orobor $\left.\mathrm{N} 1{ }^{\circledR}\right)$.
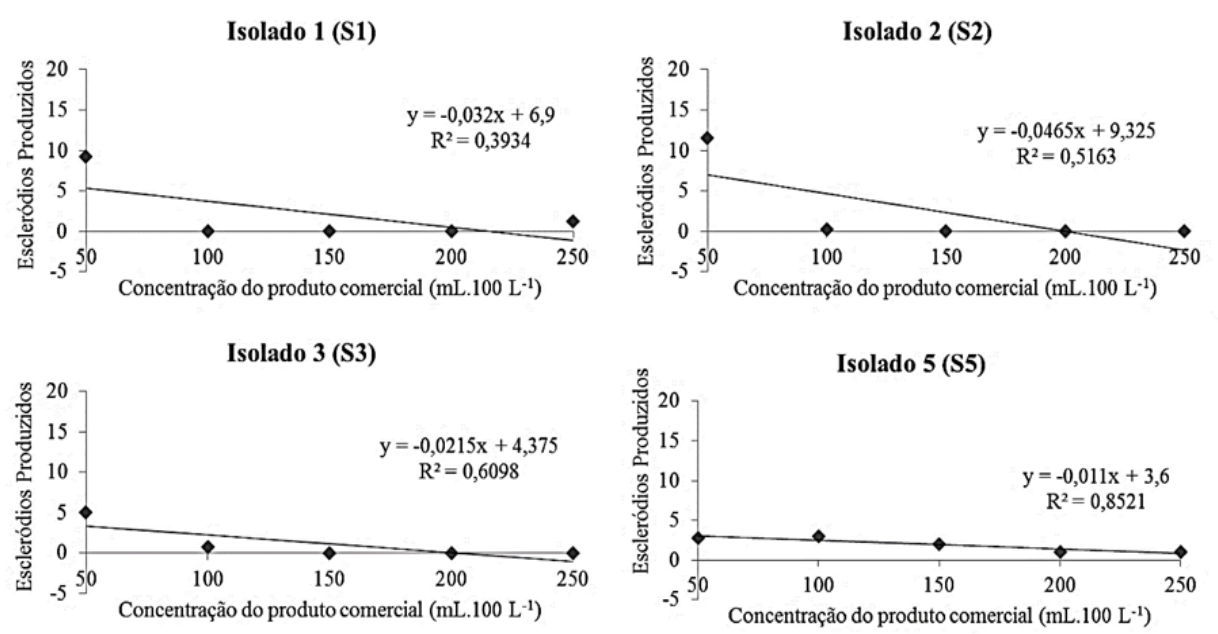

Figura 3. Produção de escleródios dos isolados de Sclerotinia sclerotiorum, aos 14 dias da implantação do experimento, em relação às concentrações do fertilizante foliar (Orobor $\mathrm{N} 1^{\circledR}$ ). 
A redução do índice de crescimento micelial do patógeno sobre o meio de cultura BDA (Figura 2) pode ser explicada pela existência de $\mathrm{N}$ e B na composição do fertilizante foliar. Nojosa et al. (2009) não verificaram inibição micelial de Phoma costarricensis pelo uso de fertilizante foliar comercial com boro, cobre, enxofre, manganês e zinco, porém, constataram menores valores de severidade da doença em cafeeiro. A inibição verificada neste trabalho pode ter sido efeito das concentrações empregadas ou de possível interação entre os nutrientes e o óleo essencial da casca de laranja existentes no fertilizante foliar empregado. Gomes et al. (2014) relataram atividade antifúngica de óleos essenciais de cinco espécies de Citrus sobre o crescimento e/ou inibição micelial sobre os patógenos Fusarium oxysporum e Alternaria alternata. Estes autores observaram que a inibição do crescimento aumentou proporcionalmente com o aumento das concentrações dos óleos essenciais.

À medida em que o IVCM reduziu, houve aumento do PICM para todas as concentrações avaliadas (Figuras 1 e 2). O mesmo foi verificado por Teixeira et al. (2012), onde os óleos essenciais das cascas frescas e secas de citrumelo proporcionaram inibição micelial do fungo $S$. sclerotiorum dependente das concentrações testadas, verificando o efeito-dose dependente e evidenciando desta maneira, seu efeito antimicrobiano.

Foi possível notar que o produto inibiu nas diferentes concentrações testadas o S. sclerotiorum, e interferiu diretamente na velocidade de colonização do meio de cultura. Acredita-se no sinergismo entre o boro, nitrogênio e o óleo da casca de laranja do fertilizante empregado, que provavelmente atuaram diretamente na membrana citoplasmática (BURT, 2004; BAKKALI et al., 2008).

Estudos realizados por Sharma e Tripathi (2006) mostraram atividade fungicida do óleo da casca de Citrus sinensis, atribuída ao limoneno (molécula pertencente à família dos terpenos) e o sinergismo dos diferentes compostos presentes no óleo essencial, sobre 10 patógenos de pós-colheita Também foi verificado, por Teixeira et al. (2012), a ação antimicrobiana dos monoterpenos, limoneno, sequiterpeno cíclico e transcariofileno, que são componentes do óleo essencial da casca de citrumelo Swingle, sobre os patógenos Fusarium oxysporum e Colletotrichum musae.

O produto avaliado também influenciou a produção de escleródios em função dos isolados (Figura 3), sendo que houve completa inibição nas concentrações de 215,6 mL $100 \mathrm{~L}^{-1}$ (S1), 200,5 mL $100 \mathrm{~L}^{-1}$ (S2) e 203,5 $\mathrm{mL} 100 \mathrm{~L}^{-1}(\mathrm{~S} 3)$. Houve diminuição da formação de escleródios pela exposição do fungo ao fertilizante foliar avaliado (Figura 3). Acredita-se que isto se deu pela redução do crescimento micelial do patógeno pois, de acordo com Townsend e Willetts (1954), a formação dos escleródios se dá pela agregação de hifas de Sclerotinia sclerotiorum.

Detectou-se interação significativa $(p \leq 0,05)$ das concentrações do fertilizante foliar sobre a formação carpogênica dos escleródios no solo. Tanto os dados de porcentagem de germinação carpogênica quanto os dados de número de estipes formados e número de apotécios formados se ajustaram ao modelo linear (Figuras 4 e 5).
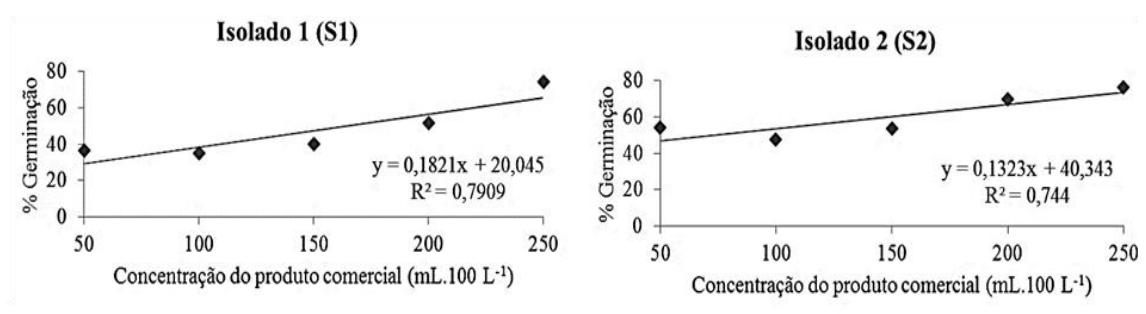

Isolado 3 (S3)
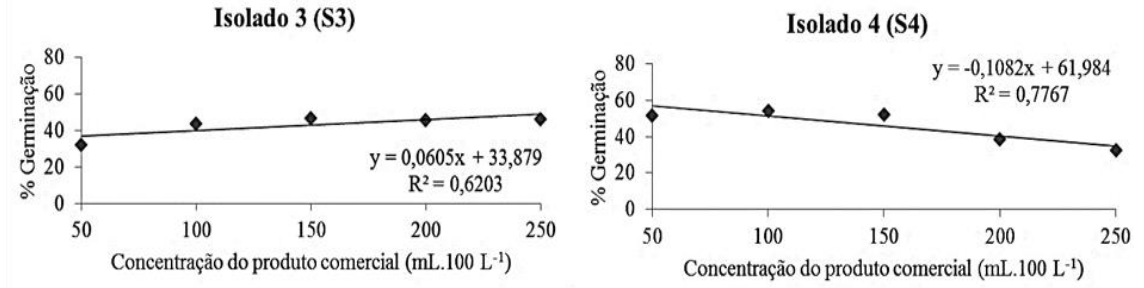

Isolado 5 (S5)

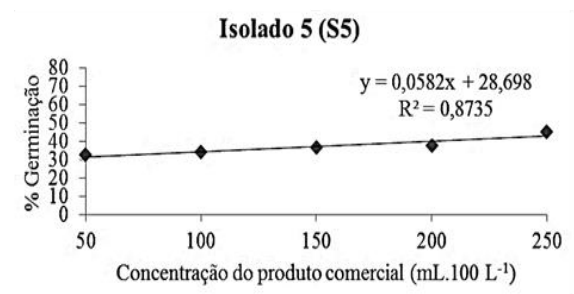

Figura 4. Germinação carpogênica (\%) total dos isolados de Sclerotinia sclerotiorum em função das concentrações do fertilizante foliar (Orobor $\mathrm{N}^{\circledR}{ }^{\circledR}$ ). 

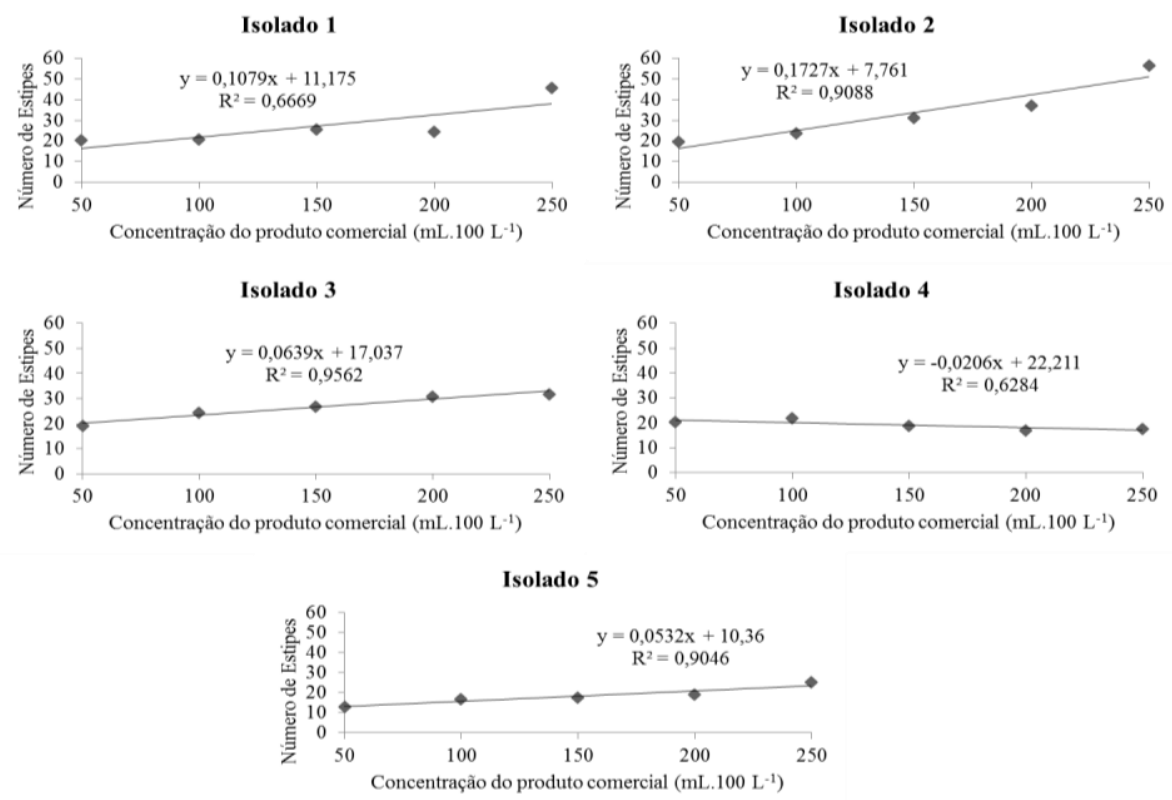

Figura 5. Formação de estipes formados de Sclerotinia sclerotiorum, em função das concentrações do fertilizante foliar (Orobor $\mathrm{N} 1^{\circledR}$ )
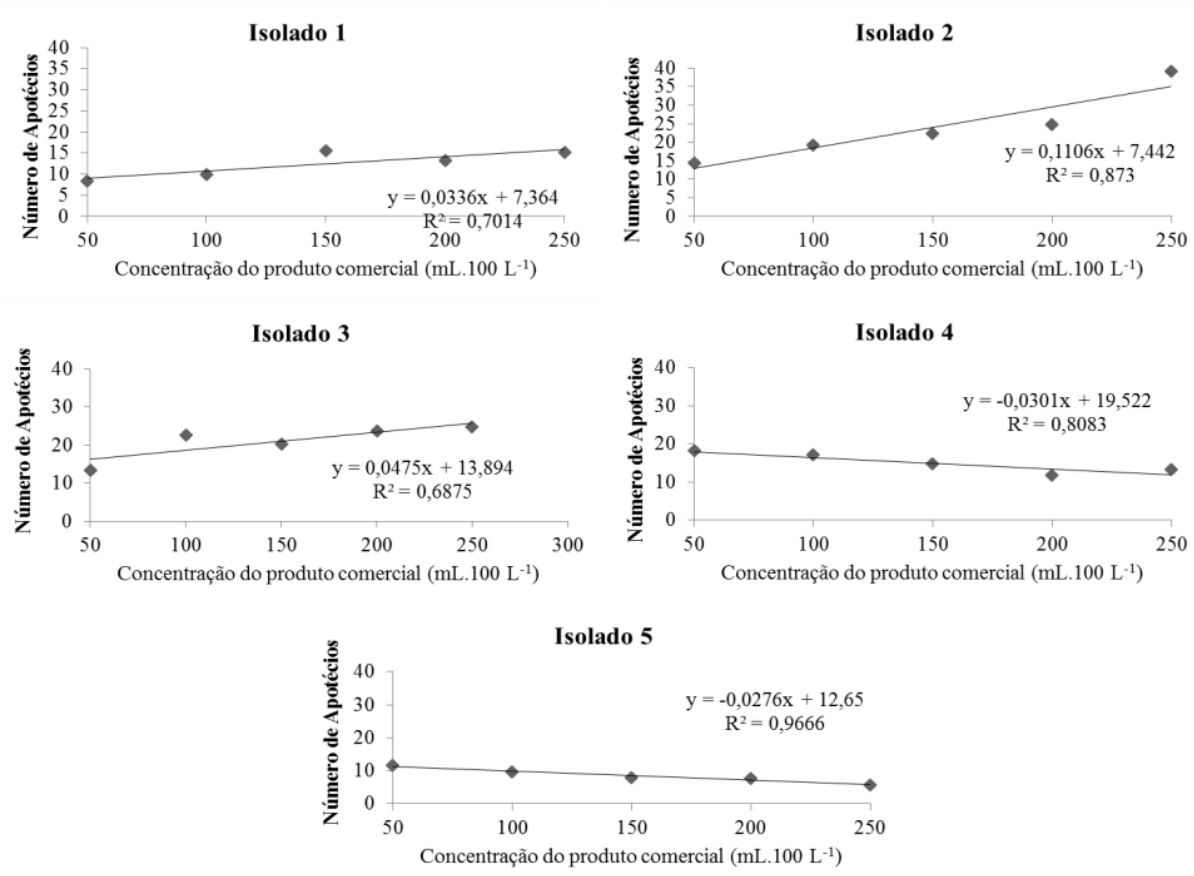

Figura 6. Formação de apotécios de Sclerotinia sclerotiorum, em função das concentrações do fertilizante foliar (Orobor N1®).

O fertilizante foliar inibiu a germinação carpogênica apenas do isolado 4 (Figura 4), sendo que a maior concentração permitiu a germinação de $34,9 \%$ dos escleródios. Nos isolados 1, 2, 3 e 5, o produto estimulou a germinação carpogênica dos mesmos, pois a testemunha apresentou menor porcentagem de germinação em relação às concentrações utilizadas. Zanella et al. (2015), ao avaliarem o efeito de extratos metanólicos de Annona cacans, Annona coriacea e Annona dioica sobre a germinação carpogênica de
Sclerotinia sclerotiorum, também constataram no tratamento testemunha, menor germinação em relação aos tratamentos.

Conforme estes autores, o efeito estimulante da germinação carpogênica de alguns extratos pode ser positivo no manejo do mofo branco por estimular a germinação dos escleródios em culturas não hospedeiras, pois diminui o inóculo na área.

Os comportamentos variados dos isolados utilizados frente ao produto comercial podem estar relacionados à 
grande variabilidade genética encontrada nos isolados de S. sclerotiorum. Abreu e Souza (2015) contataram variabilidade morfológica, patogênica, fisiológica e molecular entre dezenas de isolados deste patógeno coletados em lavouras comerciais de feijoeiro no Brasil.

A variação da produção de estipes (Figura 5) e apotécios (Figura 6) indicaram diferenças na sensibilidade de $S$. sclerotiorum às concentrações do fertilizante foliar. Com exceção do isolado 4 , todos os outros tiveram aumento na produção de estipes conforme houve o aumento da concentração do fertilizante foliar (Figura 5). A formação de apotécios foi maior com o aumento da concentração do produto nos isolados 1,2 e 3 , enquanto que para os isolados 4 e 5 as maiores concentrações reduziram o número destas estruturas. Apesar de não inibir a formação das estruturas reprodutivas, houve redução na formação de apotécios e, provavelmente, menor quantidade de ascósporos produzidos. Observando-se este comportamento em condições de campo, aventa-se a possibilidade de o produto diminuir a taxa de progresso da doença (ABAWI; GROGAN, 1979)

Os resultados obtidos neste trabalho indicaram efeito significativo do fertilizante foliar Orobor $\mathrm{N} 1{ }^{\circledR}$ sobre o desenvolvimento de $S$. sclerotiorum em função do isolado avaliado. São necessários experimentos ao campo para se avaliar a eficácia deste produto na redução da severidade do mofo branco em plantas de interesse econômico.

Verificou-se interação significativa entre concentrações e isolados para as variáveis estudadas.

O produto reduziu o desenvolvimento vegetativo e a produção de escleródios de Sclerotinia sclerotiorum.

De forma geral, houve aumento da produção de estipes e apotécios, assim como da germinação carpogênica da maioria dos isolados avaliados.

\section{Referências Bibliográficas}

ABAWI, G. S.; GROGAN, R. G. Epidemiology of diseases caused by Sclerotinia species. Phytopathology, St. Paul, v. 69, n. 8, p. 899-904, 1979.

ABREU, M. J.; SOUZA, E. A. Investigation of Sclerotinia sclerotiorum strains variability in Brazil. Genetics and Molecular Research, Ribeirão Preto-SP, v. 18, n. 2, p. 68796896, 2015.

ABBASI, P. A.; SOLTANI, N.; CUPPELS, D. A.; LAZAROVITS, G. Reduction of bacterial spot disease severity on tomato and pepper plants with foliar applications of ammonium lignosulfonate and potassium phosphate. Plant Disease, St. Paul, v. 86, n. 11, p. 1232-1236, 2002.

ABBOTT, W. S. A method of computing the effectiveness of an insecticide. Journal of Economic Entomology, Lanham, v. 18, n. 1 , p. $265-267,1925$.
ABDULLAH, M. T.; ALI, N. Y.; SULEMAN, P. Biological control of Sclerotinia sclerotiorum (Lib.) De Bary with Trichoderma harzianum and Bacillus amyloliquefaciens. Crop Protection, Amsterdam, v. 27, p. 1354-1359, 2008.

BAKKALI, F.; AVERBECK, S.; AVERBECK, D.; IDAOMAR, M. Biological effects of essential oils-a review. Food and Chemical Toxicology, Amsterdam: Elsevier, v. 46, n. 2, p. 446-475, 2008.

BOLAND, G. J.; HALL, R. Index of plant hosts of Sclerotinia sclerotiorum. Canadian Journal of Plant Pathology, Guelph, v. 16, n. 2, p. 93-108, 1994.

BOLTON, M. D.; THOMMA, B. P. H. J.; NELSON, B. D. Sclerotinia sclerotiorum (Lib.) de Bary: biology and molecular traits of a cosmopolitan pathogen. Molecular Plant Pathology, Anglia, v. 7, n. 1, p. 01-16, 2006.

BUCK, G. B.; KORNDÖRFER, G. H.; NOLLA, A.; COELHO, L. Potassium silicate as foliar spray and rice blast control. Journal of Plant Nutrition, London, v. 31, n. 2, p. 231-237, 2006.

BURT, S. Essential Oils: their antibacterial properties and potential applications in foods - a review. International Journal of Food Microbiology, Amsterdam: v. 94, n. 3, p. 223-253, 2004.

CASSETARI NETO, D.; MACHADO, A. Q.; SILVA, R. A. Manual de doença da soja. São Paulo-SP: Cheminova Brasil Ltda, 2010. 57 p.

DELGADO, G. V.; MARTINS, I.; MENÊZES, J. E.; MACEDO, M. A.; MELLO, S. C. M. Inibição do crescimento de Sclerotinia sclerotiorum por Trichoderma spp. in vitro. Brasília-DF: Embrapa Recursos Genéticos e Biotecnologia, 2007. 12 p. (Boletim de pesquisa e desenvolvimento, 214).

GARCIA, R. Á.; JULIATTI, F. C.; BARBOSA, K. A. G.; CASSEMIRO, T. A. Atividade antifúngica de óleo e extratos vegetais sobre Sclerotinia sclerotiorum. Bioscience Journal, Uberlândia-MG, v. 28, n. 1, p. 48-57, 2012 b.

GARCiA, R. Á.; JUliAtTi, F. C.; CASSEMiRO, T. A. Produção de escleródios de Sclerotinia sclerotiorum (LIB.) de Bary em meio de cultura. Bioscience Journal, UberlândiaMG: v. 28, n. 1, p.1-7, 2012a.

GOMES, M. S., CARDOSO, M. G., SOARES, M. J., BATISTA, L. R., MACHADO, S. M. F., ANDRADE, M. A., AZEREDO, C. M. O., RESENDE, J. M. V. RODRIGUES, L. M. A. Use of essential oils of the genus Citrus as biocidal agents. American Journal of Plant Sciences, Wuhan, v. 5, n. 3, p. 299-305, 2014.

GUÉVEL, M. H.; MENZIES, J. G.; BÉLANGER, R. R. Effect of root and foliar applications of soluble silicon on powdery mildew control and growth of wheat plants. European Journal of Plant Pathology, Wageningen, v. 119, n. 4, p. 429-436, 2007.

HOMECHIN, M. Plantas daninhas hospedeiras de Sclerotinia sclerotiorum. Fitopatologia Brasileira, Brasília-DF, v. 7, n. 3, p. 472, 1982. 
NAPOLEÃO, R.; CAFÉ FILHO, A. C.; LOPES, C. A.; NASSER, L. C. B.; MAROUELLI, W. A. Efeito da frequência de rega e da umidade do solo sobre a germinação carpogênica de Sclerotinia sclerotiorum. Summa Phytopathologica, Botucatu-SP, v. 33, n. 1, p.80-82, 2007.

NOJOSA, G. B. A.; RESENDE, M. L. V., BARGUIL, B. M.; MORAES, S. R. G.; VILAS BOAS, C. H. Efeito de indutores de resistência em cafeeiro contra a mancha de Phoma. Summa Phytopathologica, Botucatu-SP, v. 35, n. 1, p. 60-62, 2009.

OLIVEIRA, J. A. Efeito do tratamento fungicida em sementes e no controle de tombamento de plântulas de pepino (Cucumis sativus L.) e pimentão (Capsicum annum L.). Ciência e Prática, Lavras-MG, v. 16, n. 1, p. 42-47, 1992.

PAULA JÚNIOR, T. J.; VIEIRA, R. F.; TEIXEIRA, H.; CARNEIRO, J. E. S. Foliar application of calcium chloride and calcium silicate decreases white mold intensity on dry beans. Tropical Plant Pathology, Brasília-DF, v. 34, n. 3, 171-174, 2009.

REUVENI, R.; DOR, G.; REVEUNI, M. Local and systemic control of powdery mildew (Leveillula taurica) on pepper plants by foliar spray of mono-potassium phosphate. Crop Protection, Amsterdam, v. 17, n. 9, p. 703-709, 1998.

SHARMA, N.; TRIPATHI, A. Fungitoxicity of the essential oil of Citrus sinensis on post-harvest pathogens. World
Journal of Microbiology and Biotechnology, Oxford, v. 22, n. 6, p. 587-593, 2006.

SUMIDA, C. H.; CANTERI, M. G.; PEITL, D. C.; TIBOLLA, F.; ORSINI, I. P.; ARAÚJO, F. A.; CHAGAS, D. F.; CALVOS, N. S. Chemical and biological control of Sclerotinia stem rot in the soybean crop. Ciência Rural, Santa Maria-RS, v. 45, n. 5, p. 760-766, 2015.

TEIXEIRA, M. L.; GRAÇAS, C., M.; SOUZA, P. E.; FERNANDES, S. M. Citrumelo Swingle: Caracterização química, atividade antioxidante e antifúngica dos óleos essenciais das cascas frescas e secas. Magistra, Salvador-BA, v. 24, n.3, p. 194-203, 2012.

TOWNSEND, B. B.; WILLETTS, H. J. The development of sclerotia of certain fungi. Transactions of the British Mycological Society, Amsterdam, v. 37, n. 3, p. 213-221, 1954.

WORDELL FILHO J. A.; STADNIK M. J. Controle da mancha acinzentada da cebola e seu impacto sobre a qualidade de mudas. Horticultura Brasileira, Brasília-DF, v. 24, n. 4, p. 437-441, 2006.

ZANELLA, C. D. S.; GAVASSONI, W. L.; BACCHI, L. M. A.; FORMAGIO, A. S. N. Activity of plant extracts on the carpogenic germination and mycelial growth of Sclerotinia sclerotiorum. Arquivos do Instituto Biológico, São PauloSP, v. 82, p. 1-8, 2015. 